\title{
PENGARUH FASE BULAN TERHADAP HASIL TANGKAPAN LOBSTER (Panulirus homarus) di TELUK PALABUHANRATU KABUPATEN SUKABUMI
}

\section{MOON PHASE EFFECT OF LOBSTER (Panulirus homarus) CATCHES IN PALABUHANRATU GULF, SUKABUMI DISTRICT}

\author{
Arik Permana $^{1}$, Ronny I Wahju ${ }^{2}$, Deni Achmad Soeboer ${ }^{3}$ \\ 1,3 Stasiun Lapang Kelautan \\ ${ }^{2}$ Depertemen Pemanfaatan Sumberdaya Perikanan, \\ Fakultas Perikanan dan Ilmu Kelautan, Institut Pertanian Bogor \\ Korespondensi: arik.ikan@gmail.com,rwahyu06@gmail.com
}

\begin{abstract}
Sukabumi distric is one of the potensial areas lobster producer in Indonesia, particulary in the gulf region Palabuhanratu, one species of lobster is Panulirus. homarus usually called in bahasa Indonesia is Lobster Hijau Pasir. So many research on the another places is the moon phases give influence to catch of lobster. This study is want to observe, the influence of the moon phase to the lobster catches especially for $P$. homarus species in the Pelabuhanratu district. And also the influence the moon phase to the size of P. homarus lobster. Data is collected from the collecting lobster catches from August to December 2015. The moon phase are divides in 4 phases, as the semi-bright moon phase (phase 1), full moon (phase 2), semi dark (phase 3), and full dark (phase 4), the phases of moon is take from List of Nautical Almanac. The size of lobster is divided in to 3 sizes, as KK (0.30-0.99 grs/pc), SPK (100-200 grs/pc), and SPB (200 grs $\mathrm{Up} / \mathrm{pc}$ ). The results of this study is showed the catch of Panulirus homarus lobster in Pelabuhanratu district, the moon phase was not give different influence significantly, it's shown from calculations of the statistic $\mathrm{P}=0.8917(\mathrm{P}>0.05)$. The Lobster caught in all the phases of the moon, and the biggest one in the semi-bright moon phase (phase 1) as big as $41.90 \pm 11.7$ (SE) kilograms. If base on the sizes, that many Lobster caught in KK (0.30-0.99 grs/pc) and SPK (100-200 grs/pc). If the accordance of calculation of catch trend, has started an increase of catches in September. This conditions is in conjunction with the start of the rainy season/west season. The conclusions of this study, that the moon phase is not give influence to the total catches of lobster $P$. homarus, but it is predicted there are other factors is influence it is a local environmental factors that have a major influence on the total catches of lobster P. homarus.
\end{abstract}

Keyword: lobster, moon phases, Palabuhanratu, Panulirus homarus

\section{ABSTRAK}

Kabupaten Sukabumi merupakan salah satu daerah potensial penghasil lobster di Indonesia, khususnya di wilayah Teluk Palabuhanratu, lobster yang banyak tertangkap di daerah ini adalah jenis lobster panulirus homarus dikenal dengan nama lobster Hijau pasir dalam bahasa Indonesia, banyak penelitian yang di lakukan ditempat lain menyatakan bahwa fase bulan memberikan pengaruh dan tidak pengaruh terhadap hasil tangkapan lobster. Maka penelitian ini mengamati pengaruh fase bulan terhadap hasil tangkapan lobster dan pengaruh fase bulan terhadap ukuran, yang berada di wilayah teluk Palabuhanratu. Data yang di kumpulkan merupakan data dari hasil tangkapan yang di kumpulkan pada pengumpul lobster dari mulai bulan Agustus sampai bulan Desember 2015. Fase bulan di bagi kedalam 4 kwadran, fase bulan semi terang (Kwadran I), fase bulan purnama (Kwadran II), fase bulan semi gelap (Kwadran III) dan fase bulan gelap (Kwadran IV) data fase bulan di ambil dari daftar almanak nautika. Ukuran lobster yang tertangkap di bagi kedalam 3 ukuran yaitu KK (0.30-0.99 gram/ekor), SPK (100-200 gram/ekor) dan SPB ( 200-up gram/ekor). Hasil penelitian ini menunjukan bahwa hasil tangkapan lobster P. homarus di teluk Palabuhanratu tidak memberikan pengaruh yang berbeda secara signifikan terhadap fase bulan, ini berdasarkan hasil uji statistik dimana nilai $\mathrm{P}=$ 0.8917 ( $\mathrm{P}>0.05)$. Lobster tertangkap di semua fase bulan dan terbanyak di fase bulan semi terang (kwadran I) sebesar $41.90 \pm 11.7$ (SE) kg. dimana lobster tersebut banyak tertangkap pada ukuran KK (0.30-0.99 gram/ekor) dan SPK (100200 gram/ekor), berdasarkan trand hasil tangkapan selama setahun menggambarkan terjadi peningkatan produksi hasil tangkapan lobster pada bulan September sampai bulan Desember, hal ini bersamaan pula dengan di mulainya musim penghujan/musim barat.

Kata kunci: fase bulan, lobster P. homarus, Palabuhanratu 


\section{PENDAHULUAN}

\section{Latar belakang}

Spiny Lobster (Panulirus sp.) dikenal dengan nama lobster secara umum merupakan salah satu potensi sumberdaya perikanan yang banyak tersebar di Indonesia, lobster menempati urutan pertama komoditas ekspor dari kelompok crustacea dan mollusca (Nurjanah et al. 2011). Di Indonesia terdapat 6 jenis lobster yang tertangkap dan di jual belikan (Nuraini dan Sumiono 2008) yaitu: Lobster Hijau pasir (Panulirus homarus), lobster Batu (Panulirus penicilatus), lobster Bunga (Panulirus longipes), lobster Hijau bambu (Panulirus versicolor), lobster Bambu coklat (Panulirus plyphagus), dan lobster Mutiara (Panulirus ornatus).

Penyebaran lobster di Indonesia meliputi perairan pantai selatan Bali, Nusa Tenggara Timur, Sulawesi Selatan, Maluku dan Irian Jaya. Beberapa tempat di pulau jawa yang dijadikan pusat pengumpulan lobster antara lain Binuangen, Palabuhanratu, Pangandaran, Pacitan, Blitar, Tabanan, Jembrana (Bali), Lempasing, Bandar Lampung dan beberapa daerah di Indonesia timur (Suryaningrum et al. 2001).

Kabupaten Sukabumi merupakan salah satu daerah potensial penghasil lobster di Indonesia, khususnya di wilayah Teluk Palabuhanratu, meskipun produksinya masih relatif sedikit sekitar 28.76 ton pada tahun 2009 atau hanya sekitar 0.05\% dari produksi nasional (Diskalut Kab. Sukabumi 2010). Lobster tersebut ditangkap di beberapa lokasi sekitar wilayah Teluk Palabuhanratu, diantarnya wilayah perairan Cisolok, Karang Hawu, Karang De'et, Cimandiri, Sanggra Wayang, Jampang dan Karang Hantu (Diskanlutkan Kab. Sukabumi, 2008).

Guna memenuhi permintaan pasar akan ke butuhan lobster, sebagai pemasok utamanya di dapat dari hasil penangkapan nelayan. Keberhasilan penangkapan lobster di pengaruhi oleh berbagai faktor yang diantaranya; waktu penangkapan, tempat atau daerah penangkapan dan alat tangkap yang di gunakan. Nelayan lobster melakukan kegiatan penangkapan di berbagai daerah perairan Indonesia menggunakan beragam alat tangkap dan teknik penangkapan yang disesuaikan dengan kondisi perairan dari masing-masing daerah potensial lobster. Alat tangkap yang umum digunakan oleh nelayan untuk menangkap lobster di perairan pantai selatan Pulau Jawa antara lain jaring ampar, jaring sirang, bottom gillnet, trammel net, pukat pantai, dogol, tombak, dan bubu atau perangkap (Sondita 1992).

Salah satu jenis lobster yang berpotensi besar adalah jenis lobster Hijau pasir ( $P$. homarus), hidup di perairan pantai yang jernih, dangkal, berkarang serta pada celah-celah batu. Lobster bersifat nokturnal atau aktif di malam hari, di temukan dalam kelompok dan bergerombol (Chan 1998). Faktor cahaya sangat mempengaruhi kehidupan lobster (Hemkind 1980). Hal ini disebabkan oleh sifat nokturnal lobster yang memulai aktivitas sebelum matahari terbenam bertambah meningkat pada malam hari dan mengurangi aktivitasnya menjelang matahari terbit. Sebagian besar hewan air memanfaatkan bulan sebagai acuan dalam melakukan aktivitas ruaya secara vertikal atau horizontal serta aktivitas yang lain (Able 1980).

Kegiatan penangkapan lobster dengan alat tangkap berbahan jaring dilakukan pada malam hari dengan cara menebar/ memasang alat tangkap semalaman penuh, sehingga kondisi lingkungan pada malam hari sangat dominan mempengaruhinya, dan salah satunnya adalah pengaruh cahaya bulan. Kondisi pencahayaan bulan akan berbeda di setiap waktunya, untuk memudakan pengelompokan penerangan cahaya bulan dikelompokan berdasarkan umur bulan yang di kenal dengan fase bulan, sumber pengelompokan fase bulan di ambil dari data almanak nautika. Informasi ini penting bagi nelayan dalam melakukan kegiatan penangkap sebagai bahan pertimbangan dalam menentukan waktu yang tepat untuk menangkap lobster.

Pengkajian dampak fase bulan terhadap hasil tangkapan (Kanciruk 1980) menyatakan bahwa hasil tangkapan untuk jenis lobster $P$. japonicus dan P.argus di pengaruhi oleh fase bulan dan faktor lainnya termasuk suhu dan tinggi gelombang, sedangkan (Yamakawa et al. 1994) menyatakan tidak adanya pengaruh antara fase bulan dan hasil tangkapan $P$. argus di teluk Batobano Cuba, (Lopetegui et al. 2011) dengan ketidak konsistenya pengamatan hasil tangkapan terhadap fase bulan maka menyarankan dampak lingkungan lokal yang berpengaruh besar terhadap hasil tangkapan. Perbedaan pengamatan dari beberapa hasil penelitian di atas mendorong untuk melakukan 
penelitian tentang pengaruh fase bulan terhadap hasil tangkapan lobster $P$. homarus di wilayah Teluk Palabuhanratu Kabupaten Sukabumi Jawa Barat, begitu pula data yang tersaji dari dari dinas Kelautan dan Perikanan merupakan gambaran umum tentang produksi hasil tangkap nelayan, belum menggambarkan secara rinci tentang informasi yang spesifik mendukung kegiatan penangkapan misalkan; pola musim penangkapan, komposisi jenis dan ukuran (layak tangkap).

Penelitianinibertujuan untukmengkaji lebih dalam tentang hasil tangkapan lobster yang didasarkan pada pengaruh fase bulan terhadap hasil tangkapan, tren musim penangkapan, serta komposisi hasil tangkapan, dengan harapan hasil penelitian ini bisa dijadikan sebagai sumber informasi bagi nelayan dalam melakukan kegiatan penangkapan agar kegiatan penangkapan lebih berhasil serta menguntungkan, juga sebagai bahan pertimbangan pemerintah dalam menentukan dasar kebijakan tentang konservasi sumberdaya perikanan lobster yang tetap lestari. Data yang di gunakan dalam penelitian ini merupakan data tangkpan lobster nelayan di sekitar Teluk Palabuhanratu selama satu tahun (data 2013), pengambilan data dilakukan dengan metode survei di lokasi penelitian yang dilakukan sejak bulan Agustus-Desember 2015.

\section{METODE PENELITIAN}

Penelitian dilakukan pada bulan Agustus-Desember 2015. Lokasi penelitian dilakukan perairan wilayah Teluk Palabuhanratu, Kabupaten Sukabumi, Provinsi Jawa Barat. Lokasi dapat dilihat pada (Gambar 1). Peralatan yang digunakan meliputi kamera, GPS, Meteran, Timbangan, Jangka Sorong, Peta lokasi penangkapan, Alamanak Nautika 2013.

Jenis lobster yang di jadikan sebagai bahan penelitian (Gambar 2) adalah lobster dari jenis Hijau pasir ( $P$. homorus) yang merupakan salah satu spesies lobster yang tertangkap banyak di wilayah perairan Teluk Palabuhanratu dari enam jenis lobster lainya.

\section{Pengumpulan data}

Data yang dikumpulkan berupa data primer dan data sekunder. Data primer merupakan data hasil tangkapan harian nelayan lobster di sekitar wilayah teluk
Palabuhanratu yang disetorkan kepada pengumpul untuk ditimbang, disortir berdasarkan ukuran. Data sekunder yang dikumpulkan berupa data produksi hasil tangkapan lobster yang diterbitkan oleh Dinas Kelautan dan Perikanan Kabupaten Sukabumi, buku literatur tentang lobster, Almanak Nautika Tahun 2013 (Dishidros TNI-AL 2013), hasil-hasil penelitian tentang lobster di perairan Teluk Palabuhanratu dan penelitian lobster di tempat lainnya.

\section{Pengolahan data}

Data yang terkumpul dibuat dalam tabulasi data, disusun berdasarkan tanggal dan bulan secara runut waktu, kemudian dikelompokkan berdasarkan jenis dan ukurannya, untuk memudakan penggolongan hasil tangkapan maka digunakan istilah penamaan yang sudah di kenal oleh para nelayan beserta para pengepul lobster dan lazim digunakan dalam pemasaran lobster di sekitar Teluk Palabuhanratu. Istilah nama dan ukuran dalam pengelompokan lobster hasil tangkapan di Teluk Palabuhanratu yaitu: $(\mathrm{KK} / \mathrm{Kecil}$ Kecil $)=0.30-0.99$ gram $/$ ekor, $($ SPK/Super Kecil $)=100-199$ gram $/$ ekor, $(\mathrm{SPB} /$ Super Besar $)=200$ gram $>/$ ekor $)$.

Data hasil tangkapan yang sudah telah ditabulasi kemudian dikelompokan berdasarkan fase bulan pada saat hasil tangkapan itu didaratkan. Pengelompokan fase bulan berdasarkan ketentuan yang telah tersedia pada daftar Almanak Nautika tahun 2013. Fase bulan di kelompokan kedalam 4 fase bulan yaitu: Semi Terang (Kwadran I), Bulan Terang (Kwadran II), Semi Gelap (Kwadran III) dan Bulan Gelap (Kwadran IV).

\section{Analisis data}

Untuk mengetahui pengaruh fase bulan terhadap hasil tangkapan dianalisa menggunakan metode statistik Rancangan Acak Lengkap (RAL) dengan perlakuan pengelompokan hasil tangkapan berdasarkan ukuran (3 ukuran/sebagai perlakuan) dalam satu tahun (12 bulan) sehingga jumlah ulangannya menjadi 36 dalam 4 kelompok fase bulan produksi. Model Rancangan Acak Lengkap yaitu:

$$
Y i j=\mu+\tau i+\varepsilon i j
$$

Dengan :

Yij =Nilai peubah respon yang mendapat 
perlakuan ke-i ulangan ke-j

$\mu=$ Paramater rata-rata umum

ti $=$ Tambahan dari pengaruh perlakuan ke-i

$\varepsilon i j=$ Galat percobaan perlakuan ke-i ulangan ke-j

Sumber (Walpole 1995).

Hipotesis rancangan acak lengkap yaitu (RAL):

$$
\begin{aligned}
& \mathrm{HO}=\mathrm{ti}=0 \\
& \mathrm{H} 1=\text { minimal ada } 1 \mathrm{ti} \neq 0
\end{aligned}
$$

Uji yang dilakukan yaitu uji $F$, dengan selang kepercayaan 95\%, dimana jika Fhit > Ftab, maka tolak $\mathrm{H}_{0}$ yang berarti fase bulan akan memberikan pengaruh nyata terhadap hasil tangkapan lobster dan sebaliknya apabila Fhit $<\mathrm{F}$ tab maka terima $\mathrm{H}_{0}$, yang artinya fase bulan tidak memberikan pengaruh yang nyata terhadap hasil tangkapan lobster.

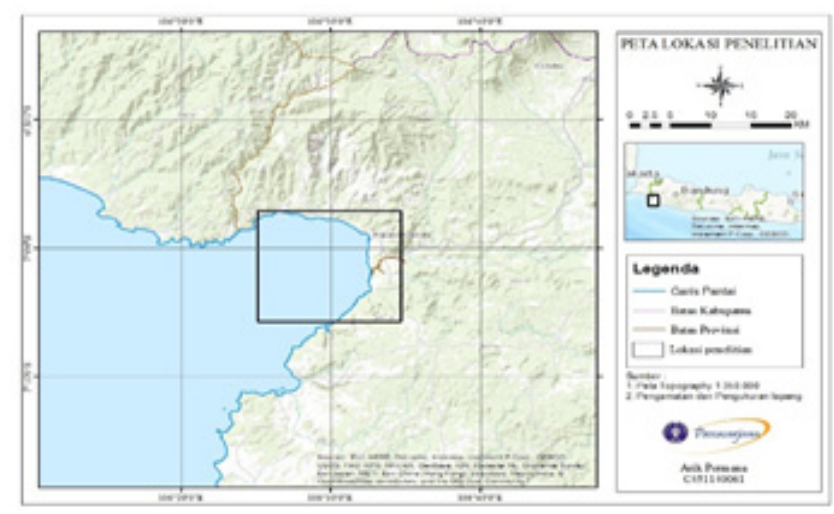

Gambar 1. Lokasi penelitian (Teluk Palabuhanratu)

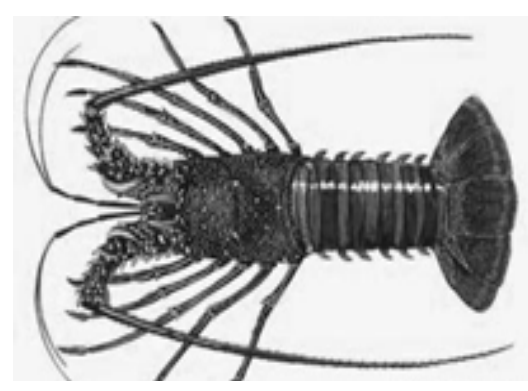

Gambar 2. Lobster hijau pasir ( $P$. homarus)

\section{HASIL DAN PEMBAHASAN}

\section{Analisis produksi dan pola hasil tangkapan berdasarkan fase bulan}

Data hasil tangkap lobster $P$. homarus yang dikelompokan kedalam masingmasing ukuran (KK, SPK, dan SPB) di susun berdasarkan tanggal tertangkapnya, kemudian di sesuaikan dengan tanggal terjadinya fase bulan, pembagian fase bulan dikelompokkan menjadi 4 kwadran fase bulan pada setiap bulannya yang dihitung selama satu tahun (12 bulan). Hasil pengolahan data dalam bentuk tabulasi hasil tangkapan dan kelompok fase bulan dapat di lihat pada (Tabel 1). Setelah dilakukan pengujian dengan metode statistik Rancangan Acak Lengkap (RAL) menghasilkan nilai rata-rata hasil tangkapan lobster beserta standar error (SE) pada setiap fase bulan. Grafik fase bulan terhadap hasil tangkapan rata-rata lobster $P$. homarus dapat di lihat pada (Gambar. 3). Nilai rata-rata hasil tangkapan untuk fase bulan I sebesar 41.90 \pm 11.70 merupakan nilai tertinggi dari jumlah hasil tangkapan lobster, fase bulan III sebesar 35.70 \pm 10.16 , fase bulan IV 34.00 \pm 8.91 dan hasil tangkap terendah pada fase bulan II sebesar $31.19 \pm 9.08$, fase bulan II merupakan fase dimana bulan terang (purnama). 
Menurut (Prasaptani 2001) pada saat fase bulan purnama lobster bergerak ke arah yang lebih dalam atau membenamkan diri kedalam subtrat dan bersembunyi di dalam karang hal ini menjadikan peluang untuk tertangkapnya lobster berkurang di fase bulan II (purnama) jika di bandingkan dengan fase bulan lainnya.

Hasil uji statistik tabel Anova (Tabel 2) antara pengaruh fase bulan terhadap hasil tangkapan lobster $P$. homorus menujukan F 0.206581 dan Fcrit 2.6669256 dengan demikian menunjukan tidak berbeda nyata antara fase bulan terhadap hasil tangkapan lobster P. homarus, karena Fcrit > F (selang kepercayaan 95\%) ini di dukung pula nilai $\mathrm{P}$-value 0.89 ( $\mathrm{P}>0.05)$.

Berdasarkan hasil penelitian diketahui bahwa tidak ada pengaruh antara fase bulan terhadap hasil tangkapan lobster selaras dengan pernyataan (Yamakawa et al. 1994) yang menyatakan bahwa dampak dari kuatnya gelombang/tinggi gelombang memberikan hasil yang meningkat pada hasil tangkapan lobster P. Japonicus pada perikanan gill net, menurut (Lopeztegui et al. 2011) mengatakan pula bahwa dengan tidak konsisten jumlah hasil tangkapan lobster dengan fase bulan maka disimpulkan bahwa fakor lingkungan lokal yang berpengaruh besar terhadap hasil tangkapan, dari pada pengaruh fase bulan.

Pola hasil tangkap lobster P. homarus setiap ukuran terhadap fase bulan di tunjukan pada (Gambar 4), dimana dapat dilihat jumlah hasil tangkapan meningkat di fase bulan semi terang (Kwadran I) dan fase bulan semi gelap (Kwadran III) berlaku untuk semua ukuran lobster yang tertangkap, sedangkan pada fase bulan purnama dan fase gelap bulan (Kwadran II dan IV) jumlah hasil tangkapan cenderung sama, jika dibandingkan dengan fase bulan semi terang dan fase bulan semi gelap (Kwadran I dan III). Sesuai dengan hasil penelitian (Srisurican et al. 2005) Hasil tangkapan lobster ( $P$. cygnus) bervariasi berdasarkan siklus bulan dengan minimum hasil tangkapan di periode bulan purnama dan maksimum hasil tangkapan di periode bulan baru terutama untuk lobster berukuran kecil yang tertangkap di perairan dangkal.

\section{Analisis komposisi dan tren hasil tangkapan}

Komposisi hasil tangkapan lobster berdasarkan ukuran yang tertangkap (Gambar 5) menggabarkan bahwa hasil tangkapan lobster Panulirus homarus tertangkap di semua fase bulan, banyak tertangkap pada ukuran KK (0.30-0.99 gram/ekor) yaitu $45.54 \%$ tertangkap di sepanjang tahun, mulai meningkat hasil tangkapannya di bulan Agustus dan mencapai puncaknya pada bulan November, untuk ukuran SPK (100-200 gram/ekor) yaitu $44.92 \%$ tertangkap sepanjang tahun, mulai meningkat hasil tangkapannya di bulan September dan puncaknya pada bulan Desember, sedangkan untuk ukuran SPB (200>) $9.5 \%$ tertangkap sepanjang tahun terjadi peningkatan hasil tangkapan pada bulan November, tetapi produksi nya sedikit.

Menurut Muljanah (1994) musim penangkapan lobter terjadi pada musim hujan, pada hari bulan gelap, terutama setelah bulan purnama. Siklus musim ini berlangsung sekitar 5 bulan per tahun. Siklus ini umumnya berlangsung antara bulan September sampai bulan Januari yang biasanya bersamaan dengan musim hujan.

Tabel 1. Jumlah hasil tangkapan (kg) lobster P. Homarus berdasarkan ukuran uuntuk setiap fase bulan

\begin{tabular}{lrrrrrrrrr}
\hline \multirow{2}{*}{ Bulan } & \multicolumn{3}{c}{ Fase Bulan I } & \multicolumn{3}{c}{ Fase Bulan II } & \multicolumn{3}{c}{ Fase Bulan III } \\
\cline { 2 - 9 } & \multicolumn{1}{c}{ KK } & \multicolumn{1}{c}{ SPK } & SPB & KK & SPK & SPB & KK & SPK & SPB \\
\hline Januari & 23.9 & 15.7 & 4.2 & 26.8 & 16.8 & 4.9 & 2.22 & 13.6 & 3.1 \\
Febrari & 9.8 & 6.9 & 5.6 & 15.5 & 10.9 & 7.2 & 17.5 & 14.4 & 5.3
\end{tabular}


Tabel 1 (lanjutan)

\begin{tabular}{lrrrrrrrrr}
\hline \multirow{2}{*}{ Bulan } & \multicolumn{3}{c}{ Fase Bulan I } & \multicolumn{3}{c}{ Fase Bulan II } & \multicolumn{3}{c}{ Fase Bulan III } \\
\cline { 2 - 9 } & \multicolumn{1}{c}{ KK } & \multicolumn{1}{c}{ SPK } & SPB & \multicolumn{1}{c}{ KK } & \multicolumn{1}{c}{ SPK } & SPB & \multicolumn{1}{c}{ KK } & \multicolumn{1}{c}{ SPK } & SPB \\
\hline Maret & 15.3 & 6.1 & 4.8 & 9.4 & 16.5 & 2.7 & 14.0 & 15.3 & 3.2 \\
April & 8.3 & 6.1 & 2.2 & 7.4 & 9.5 & 2.3 & 6.2 & 9.2 & 1.1 \\
Mei & 15.3 & 6.1 & 3.8 & 9.4 & 16.5 & 3.0 & 14.0 & 15.0 & 4.5 \\
Juni & 12.1 & 7.9 & 1.3 & 8.5 & 13.3 & 0.6 & 4.3 & 9.6 & 1.2 \\
Juli & 7.8 & 7.1 & 1.0 & 7.6 & 5.8 & 1.1 & 5.6 & 5.3 & 1.5 \\
Agustus & 8.5 & 15.3 & 4.2 & 8.0 & 16.7 & 1.6 & 7.5 & 14.6 & 2.3 \\
September & 73.5 & 54.6 & 24.1 & 17.6 & 19.5 & 13.5 & 33.5 & 51.3 & 14.5 \\
Oktober & 107.5 & 63.5 & 29.6 & 55.8 & 32.1 & 21.2 & 60.5 & 60.9 & 23.5 \\
November & 201.8 & 154.5 & 29.5 & 190.7 & 125.6 & 21.2 & 171.8 & 160.9 & 25.5 \\
Desember & 235.8 & 289.8 & 35.9 & 163.8 & 225.2 & 14.7 & 187.8 & 263.9 & 20.7 \\
Rata-rata & 60.7 & 52.8 & 12.2 & 43.4 & 42.4 & 7.8 & 45.4 & 52.8 & 8.9 \\
\hline
\end{tabular}

Sumber: Pengumpul Lobster (Data diolah 2016)

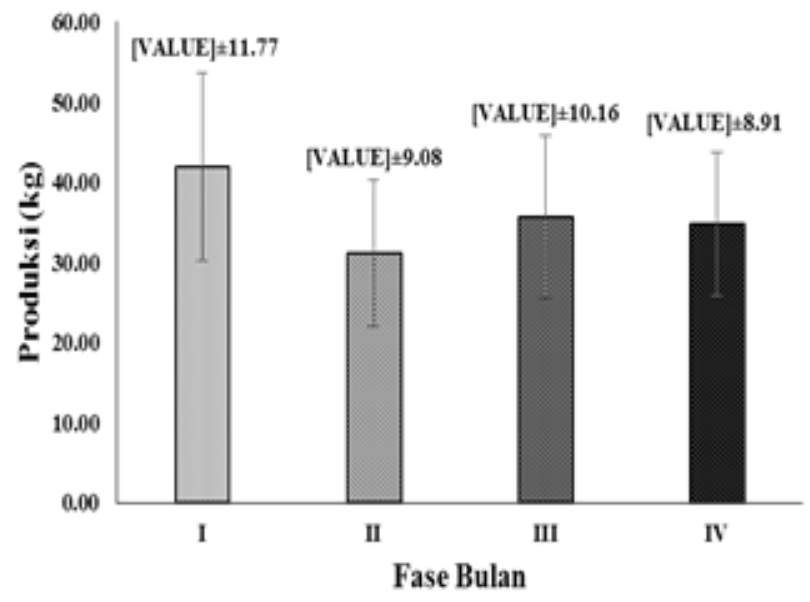

Gambar 3. Grafik fase bulan terhadap produksi rata-rara lobster P. homarus

Tabel 2. Anova pengaruh fase bulan terhadap produksi total lobster $P$. homorus

\begin{tabular}{lcccccc}
\hline Source of Variation & $S S$ & $d f$ & $M S$ & $F$ & P-value & F crit \\
\hline Between Groups & 0.215044 & 3 & 0.071681 & 0.20658113 & 0.891706043 & 2.669256 \\
Within Groups & 48.57837 & 140 & 0.346988 & & & \\
Total & 48.79341 & 143 & & $\mathrm{p}>0.05$ artinya tidak berbeda nyata \\
\hline
\end{tabular}




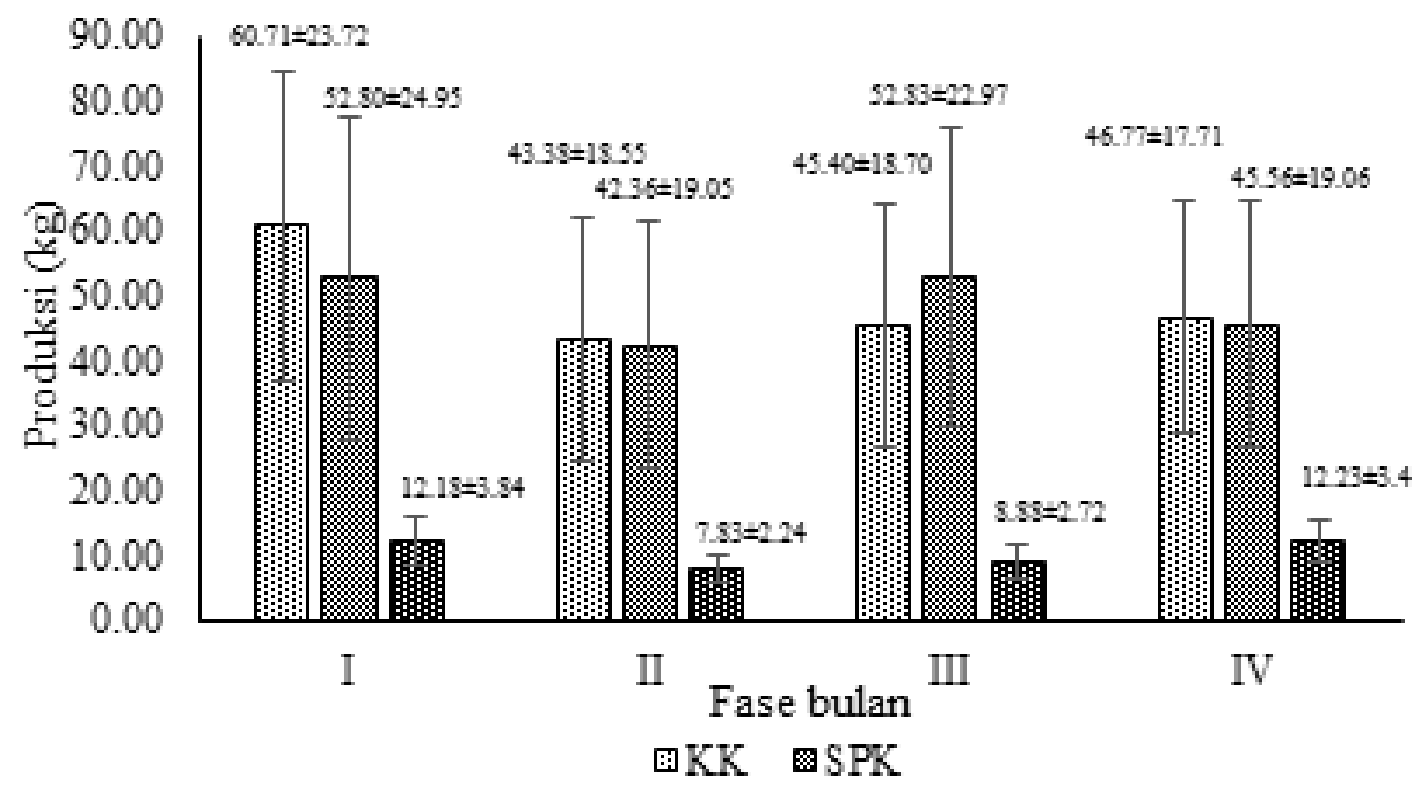

Gambar 4. Pola hasil tangkap lobster $P$. homarus setiap ukuran terhadap fase bulan

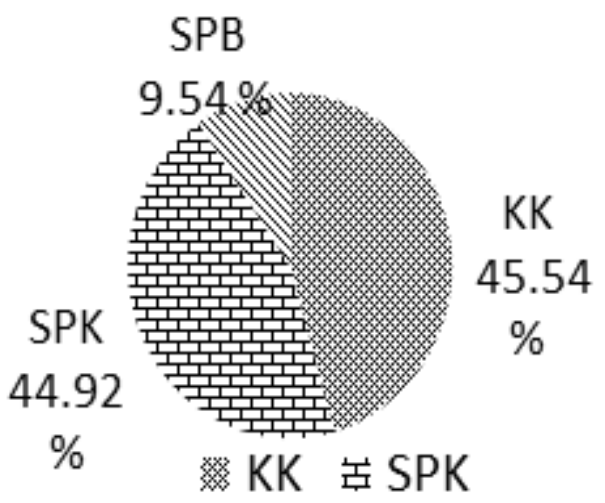

Gambar 5. Komposisi hasil tangkapan lobster P. homarus berdasarkan ukuran

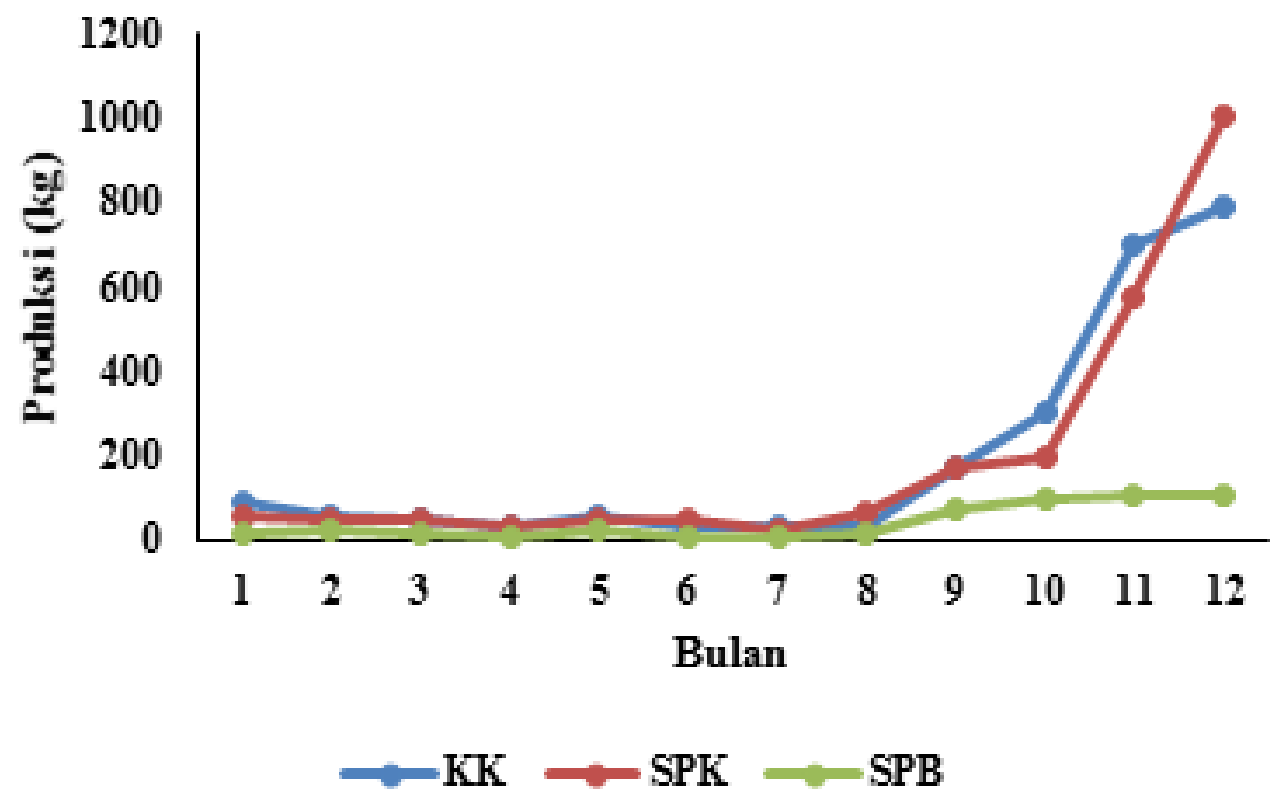

Gambar 6. Trend produksi hasil tangkapan lobster P. homarus berdasarkan ukuran 


\section{KESIMPULAN DAN SARAN}

\section{Kesimpulan}

Fase bulan tidak berpengaruh nyata terhadap jumlah total hasil tangkapan maupun ukuran lobster P. homarus . Nilai rata-rata hasil tangkapan tertinggi pada fase bulan I (bulan semi terang) dan fase bulan III (bulan semi gelap) sedangkan untuk hasil tangkap terendah berada pada fase bulan II (bulan purnama) dan fase bulan IV (bulan gelap). Hasil tangkapan lobster dengan jumlah terbanyak pada ukuran KK (45.54\%) , SPK (44.92\%) dan SPB (9.54\%) di setiap bulannya, dan peningkatan hasil tangkapan lobster terjadi di bulan September-Desember.

\section{Saran}

Perlu dilakukan penelitian lebih lanjut tentang parametrik lingkungan (suhu, arus, gelombang) yang berpengaruh terhadap hasil tangkapan lobster. Data aspek biologi seperti tingkat kematangan gonad dan panjang karapas perlu dilakukan, untuk melihat kembali hubungannya dengan keberadaan sumberdaya lobster.

\section{DAFTAR PUSTAKA}

Able PK. 1980. Mechanism of orientation, navigation and homing (Animal Migration, Orientation and Navigation). Academic Press, Inc. New York San Fransisco London.

Chan TY. 1998. Shrimps and Prawns dalam Carpenter $\mathrm{KE}, \mathrm{VH}$ Niem. eds. The living marine resources of the Western Central Pacific. Vol. 2. Cephalopods, Crustaceans, Holothurians and Sharks. Food and Agriculture Organization of the United Nations Rome.

[Dislutkan] Dinas Kelautan dan Perikanan Kabupaten Sukabumi. 2008. Analisa potensi usaha perikanan tangkap Kabupaten Sukabumi. Dinas Kelautan dan Perikanan. Kabupaten Sukabumi.

[Dislutkan] Dinas Kelautan dan Perikanan. 2010. Laporan kegiatan perikanan tangkap. Dinas Kelautan dan Perikanan Pelabuhanratu. Sukabumi.

Hemkind WF. 1980. Spiny lobster: pattems of movement In. The Biology and management of lobster Vol.II J.S. Cobb and B.F. Philips (Eds). Academic Press. New York: 349-407.

Kanciruk P (1980) Ecology of juvenile and adult Palinuridae. In: Cobb JSP BF (ed) The biology and management of lobsters. Ecology and management book II. Academic Press, New York

Lopeztegui A, Baisre JA, Capetillo N. 2011. Influence of lunar cycle on catches of spiny lobster Panulirus argus (Decapoda: Palinuridae) in the Gulf of Batabano. Cuba Rev Biol Trop 59:207216.

Muljanah I, Setiabudi E, Suryaningrum D, Wibowo S. 1994. Pemanfaatan sumberdaya lobster di Kawasan Jawa dan Bali. Jurnal Penelitian Pasca Panen Perikanan. No. 79 tahun 1994. Hall- 23. Jakarta.

Nuraini S, Sumiono B. 2008. Parameter biologi udang barong di Pantai Selatan Pangandaran Jawa Barat. Prosiding seminar Nasional Tahun $V$ hasil Penelitian Perikanan dan Kelautan UGM. Yogyakarta.

Nurjanah, Asadatun A, Kustiarah. 2011. Bahan baku hasil perairan. IPB press. Bogor.

Prasetyani. 2001. Analisa pengaruh fase bulan terhadap pola penyebaran dan aktivitas lobster (Panulirus $s p$ ) pada Bulan Juli-Agustus di Perairan Selatan Kabupaten Kebumen. [Skripsi]. Bogor: Institut Pertanian Bogor.

Sondita MFA. 1992. Eksplorasi sumberdaya lobster di Perairan Pantai Selatan Pulau Jawa. Laporan Penelitian. Fakultas Perikanan, Institut Pertanian Bogor. Bogor

Srisurichan S, Caputi N, Cross J. (2005) Impact of lunar cycle and swell on the daily catch rate of western rock lobster (Panulirus cygnus) using time series modelling. $N Z J$ Mar Freshw Res 39:749-764.

Suryanigrum TD, Utomo BSB, Wibowo S. 2001. Teknologi penanganan dan transportasi krustacea hidup. Pusat Riset Pengolahan Produk dan Sosial Ekonomi Kelautan dan Perikanan Jakarta. Jakarta.

Utami DDYU. 1999. Analisis dumberdaya dan tingkat pemanfaatan lobster (Panulirus $s p$ ) yang didaratkan di Pangandaran, Ciamis, Jawa Barat. [Skripsi]. Bogor: Institut Pertanian Bogor.

Walpole RE. 1995. Pengantar statistik. Sumantri B, penerjemah. PT. Gramedia Pustaka Utama. Jakarta. Terjemahan dari : Introduction to Statistics.

Yamakawa T, Matsumiya Y, Nishimura M, Ohnishi S (1994) Expanded DeLury's 
method with variable catchability and its application to catch-effort data from spiny lobster fishery. Fish Sci 60:5963 